\title{
THE EVALUATION OF TSH-RECEPTOR ANTIBODY \\ IN HYPERTHYROID PATIENTS TREATED WITH SURGERY OR RADIOACTIVE IODINE
}

Ahmet DIRIKOC ${ }^{1}$, F. Neslihan CUHACI ${ }^{1}$, Husniye BASER ${ }^{2}$, Cevdet AYDIN ${ }^{1}$, Oya TOPALOGLU ${ }^{1}$, Mehmet KILIC ${ }^{3}$, Seyda TURKOLMEZ ${ }^{4}$, Reyhan ERSOY ${ }^{1}$, Bekir CAKIR ${ }^{1}$

1 Yildirim Beyazit University, Faculty of Medicine, Department of Endocrinology and Metabolism, Ankara, Turkey ${ }^{2}$ Ataturk Education and Research Hospital, Department of Endocrinology and Metabolism, Ankara, Turkey

${ }^{3}$ Yildirim Beyazit University, Faculty of Medicine, Department of General Surgery, Ankara, Turkey

${ }^{4}$ Yildirim Beyazit University, Faculty of Medicine, Department of Nuclear Medicine, Ankara, Turkey

Introduction

$>$ Radioactive iodine (RAI) therapy is widely used in the treatment of hyperthyroidism, especially in patients with Graves' disease (GD), toxic multinodular goitre (TMNG) and toxic adenoma. RAI treatment can induce an increase of thyroid antibodies in GD patients. Transition of TMNG to autoimmune thyroid disease after RAI treatment has been reported. Furthermore, the appearance of TSH-receptor antibodies (TRAbs) and a relapse of hyperthyroidism after RAI treatment have been described in a few patients with TMNG. In this study, we aimed to compare the effects of surgery or RAI treatment on TRAb.

Methods

$>$ Hyperthyroid patients were divided into 3 groups; those treated with RAI in Group $1(n=23)$ had GD; those treated with RAI in Group $2(\mathrm{n}=18)$ had TMNG; and, those treated surgically in Group $3(n=12)$ had GD. Before and 12 months after RAI and surgery, sera were collected and analysed for the presence of $\mathrm{TRAb}$

\section{Results}

$>$ There were 8 patients $(34.8 \%)$ before the treatment and 14 patients after the treatment with TRAb positivity $(\mathrm{p}=0.311)$ in Group 1 . While 2 patients $(11.1 \%)$ with TRAb positivity were present in Group 2 before the treatment, there were 4 patients $(22.2 \%)$ after the treatment $(p=0.423)$. In Group 3, TRAb positivity was seen in 6 patients $(50 \%)$ and 1 patient $(8.3 \%)$ before and after the treatment, respectively $(\mathrm{p}=0.296)$ (Table 1$)$. However, there was no difference between Group 1 and 3 before the treatment as to TRAb positivity $(\mathrm{p}=0.383)$, TRAb positivity was statistically higher in Group 1 than Group 3 at month 12 of the treatment $(p=0.003)$. No difference was seen between Groups 1 and 2 before the treatment $(p=0.080)$. TRAb positivity was significantly higher in Group 1 than Group 2 at month 12 of the treatment $(\mathrm{p}=0.013)$.
Table 1. Demographic and laboratory data of the study groups

\begin{tabular}{lccc}
\hline & $\begin{array}{c}\text { Group 1 } \\
(\mathbf{n}=\mathbf{2 3})\end{array}$ & $\begin{array}{c}\text { Group 2 } \\
(\mathbf{n}=18)\end{array}$ & $\begin{array}{c}\text { Group 3 } \\
(\mathbf{n}=12)\end{array}$ \\
\hline Male/Female & $7 / 16$ & $4 / 14$ & $5 / 7$ \\
$\begin{array}{l}\text { TRAb before } \\
\text { treatment }\end{array}$ & & & \\
$\quad$ Positive & 8 & 2 & 6 \\
$\quad$ Negative & 15 & 16 & 6 \\
$\begin{array}{c}\text { TRAb after } \\
\text { treatment } \\
\text { Positive }\end{array}$ & 14 & 4 & 1 \\
\hline Negative & 9 & 14 & 11 \\
\hline
\end{tabular}

\section{Conclusion}

$>$ RAI treatment can induce autoimmunity in patients with TMNG, similar to that in patients with GD. This condition appears to be associated with the induction of TRAbs. TRAbs is a generic term for both thyroid stimulating antibodies (TSAbs) and thyroid blocking antibodies (TBAbs). The induction of Graves'-like hyperthyroidism after RAI in TMNG has been postulated to be associated with pre-existing thyroid autoimmunity, as indicated by the presence of thyroid peroxidase antibodies or low titres of TRAb in TMNG.

$>$ In this study, we observed similar ratios of TRAb positivity in patients with GD and TMNG before and 12 months after the treatment. However, we demonstrated higher TRAb positivity in GD patients treated with RAI than those treated with surgery at month 12 after the treatmet. In addition, TRAb positivity was significantly higher in GD patients treated with RAI than TMNG patients treated with RAI at month 12 of the treatment. 